\title{
Developmental dyscalculia in children and adolescents with idiopathic epilepsies in a Brazilian sample
}

\author{
Avaliação de discalculia do desenvolvimento em crianças e adolescentes com epilepsia \\ idiopática em uma amostra brasileira
}

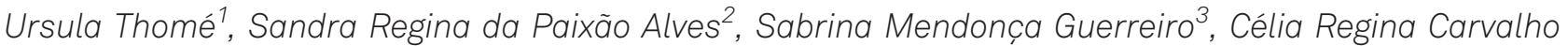
Machado da Costa ${ }^{4}$. Fernanda de Souza Moreira ${ }^{1}$, Andrea Bandeira Lima ${ }^{1}$, Maria Rita Ferreira Tavares ${ }^{1}$, Heber Souza Maia-Filho ${ }^{5}$

\begin{abstract}
Epilepsy is one of the most prevalent chronic disorders of childhood which can threaten child development and mental health. Among cognitive disorders, dyscalculia is one of the most important. In this study, 39 children and adolescents with idiopathic epilepsy underwent clinical and neuropsychological assessment to determine the intellectual level, math skills, reading and writing performance and neuropsychological profile. It was observed that the mathematical ability was below schooling expectations in a higher frequency than expected. There were no significant differences in mathematical performance among groups divided by number of antiepileptic drugs used, duration of disease and types and frequency of seizures. There was a positive correlation with intelligence quotient and attentional and reading level. These results suggest the existence not only of dyscalculia, but the concurrence of attentional and reading problems for the poor mathematical performance in this population.
\end{abstract}

Keywords: mathematical ability, dyscalculia, epilepsy, children, adolescents.

\section{RESUMO}

A epilepsia é uma das doenças crônicas mais comuns da infância que pode ameaçar o desenvolvimento infantil e saúde mental. Dos distúrbios cognitivos, a discalculia é um dos mais importantes. Neste estudo, 39 crianças e adolescentes com epilepsia idiopática, foram submetidos à avaliação clínica e neuropsicológica para determinar o nível intelectual, habilidade em matemática, leitura e escrita e perfil neuropsicológico. Observou-se que a habilidade em matemática ficou abaixo das expectativas de escolarização em uma frequência maior do que a esperada. Não houve diferenças significativas no desempenho matemático em relação ao número de drogas antiepilépticas utilizadas, duração da doença, tipo e frequência das crises. Houve uma correlação positiva com o quociente de inteligência e nível de atenção e leitura. Estes resultados sugerem a existência não só de discalculia, mas também a existência de problemas atencionais e de leitura que fatores causais para a dificuldade matemática apresentada nesta amostra.

Palavras-chave: habilidade em matemática, discalculia, epilepsia, crianças, adolescentes.

Epilepsy is a chronic neurologic disorder characterized by unprovoked recurrent seizures ${ }^{1}$. Estimation shows that around 5 and 10 million children worldwide have active epilepsy, representing about $25 \%$ of the global epilepsy population ${ }^{2}$. Forty percent of the people who develop epilepsy per year are younger than 15 years and more than $80 \%$ live in developing countries ${ }^{2}$. Population-based studies on child- hood-onset epilepsy suggest an annual incidence of 61-124/ 100,000 in developing countries and 41-50/100,000 in developed countries ${ }^{2}$.

Epilepsy is also related to behavioral, cognitive and psychiatric disorders, including autism and intellectual disability in $30 \%$ of patients ${ }^{3,4}$. There is a higher incidence of several cognitive disorders, in spite of normal intelligence,

\footnotetext{
1Programa de Pós-Graduação em Neurociências e Neurologia, Universidade Federal Fluminense, Niterói RJ, Brazil;

${ }^{2}$ Programa de Pós-Graduação Materno Infantil, Universidade Federal Fluminense, Niterói RJ, Brazil;

${ }^{3}$ Programa de Pesquisa Universitária, Universidade Federal Fluminense, Niterói RJ, Brazil;

${ }^{4}$ Programa de Pós-Graduação, Instituto de Psiquiatria, Universidade Federal do Rio de Janeiro, Rio de Janeiro RJ, Brazil;

${ }^{5}$ Programa em Neurociências e Neurologia, Unidade de Pesquisa Clínica, Departamento Materno Infantil, Universidade Federal Fluminense, Niterói RJ, Brazil. Correspondence: Ursula Thomé; Rua Prudente de Morais 642/53; 14015-100 Ribeirão Preto SP - Brasil; E-mail:ursulathom@gmail.com

Conflict of interest: There is no conflict of interest to declare.
}

Received 25 July 2013; Received in final form 16 August 2013; Accepted 06 September 2013. 
as it is possible to observe among children and adolescents with idiopathic epilepsy (CAIE). Such disorders affect learning directly or indirectly and increase the risk of school failure in these patients. Examples of these disorders are reading disorder (dyslexia), disorders of written expression (dysorthographia and dysgraphia), disorder of arithmetic (developmental dyscalculia - DD) and attention deficit and hyperactivity disorder (ADHD).

Cognitive dysfunction in epileptic patients is associated with acquired and congenital brain structure lesions, which may be stable or cause progressive and irreversible impairment. It also involves functional problems, such as interictal discharges, seizures and antiepileptic drugs (AEDs) whose interference in cognition may be fluctuant, reversible or not $^{5}$. In addition, several other factors affect the CAIE learning, including absenteeism and poor social adjustment, stigma and false beliefs in the school environment. The recognition of these issues and their influence on disease control and patient welfare is now essential in the therapeutic process of the child with epilepsy.

There are many definitions of mathematical disorders, including the one found in DSM-IV ${ }^{6,7}$. In this study, the definition used is stated by Shalev and colleagues ${ }^{6}$. Developmental dyscalculia consists of difficulty in learning mathematics, failure to acquire adequate proficiency in this cognitive domain despite normal intelligence, school attendance, motivation and emotional health ${ }^{6}$.

It is estimated that DD affects $5-6 \%$ of boys and girls, a similar frequency found in dyslexia and ADHD. It also affects more commonly children with neurological disorders, such as epilepsy, fragile $\mathrm{X}$ syndrome, $\mathrm{ADHD}$ and language disorders, including dyslexia ${ }^{6}$. In the cases where there is comorbidity, such as dyslexia and ADHD, arithmetic problems are even worse $^{6}$ and it has a significant prognostic value on these children's academic success and mental health ${ }^{8}$.

Manifestations of DD depend on the student's age and educational level ${ }^{6}$. Symptoms found more often are: error in the formation of numbers, which are often reversed; dyslexia for numbers; inability to perform simple counts, to recognize operating signals and to use linear separations; difficulties to read the value of complex numbers correctly; poor memory for basic numerical facts; difficulty to transport numbers to a suitable place to carry out calculations; inappropriate ordering and spacing of numbers in multiplication and division ${ }^{9}$.

The causes of difficulty in learning mathematics are various and involve cognitive functions such as attention, language, spatial organization and temporal orientation, memory, and executive functions, and also issues related to mathematics teaching ${ }^{10}$.

A few studies have shown a higher prevalence of dyscalculia in children and adolescents with idiopathic epilepsy ${ }^{11,12}$. Canavese et al. ${ }^{11}$ found two in ten patients with rolandic epilepsy to have dyscalculia, with the worst results in reading and writing of long or complex numbers, multiplication and counting tasks. Sart et al. ${ }^{12}$ demonstrated poor mathematical performance in thirty children with idiopathic partial epilepsies (both rolandic and occipital) in comparison to healthy children. Three categories of errors in arithmetics were found in these patients: spatial (number misalignment and dysgraphia), operational (incorrect signal reading and calculation process) and memory (numerical facts). None of the studies related the poor results to epilepsy variables nor idiopathic generalized epilepsies were studied. The aim of this study is to evaluate the mathematical ability (MA) of CAIE, to define the prevalence of DD in this sample, as well as their neuropsychological profile (intelligence, attention, reading and writing abilities). We also evaluated possible correlations between these findings and clinical variables of epilepsy, such as disease duration, seizure type, seizure frequency and use of AEDs.

\section{METHOD}

\section{Subjects}

Fifty three patients with epilepsy took part in the study. They were treated at the Pediatric Neurology Clinic of Hospital Universitário Antonio Pedro, located in a middle sized city in southeastern Brazil, Niterói. Patients attended the following inclusion criteria: diagnosis of epilepsy and idiopathic epilepsy syndrome criteria of the International League Against Epilepsy (ILAE, 1981, 1989) ${ }^{13,14}$; being between 6 and 16 years old at the time of evaluation; having regular school attendance and a minimum first grade knowledge, normal or borderline intelligence as measured by WISC-III (intelligence quocient (IQ)) greater than or equal to 70); normal clinical neurological examination and neuroimaging. The direct caregiver should be present at the time of testing and should have educational and intellectual conditions to answer the research questionnaires.

Caregivers were asked for informed consent and were interviewed about medical information related to disease duration, seizure type, seizure frequency and use of AEDs. The seizure types were classified according to ILAE criteria $(1981)^{13}$. Patients were classified according to seizure frequency in the last year in three groups: no seizures, few seizures (one to eleven seizures per year) and many seizures (patients with more than eleven attacks a year).

Fourteen patients with an IQ inferior than 70 were excluded. The final sample comprised 39 children.

\section{Assessment}

CAEI were evaluated in terms of intellectual level, math skills, reading and writing performance and attention. The tests used were WISC-III ${ }^{15}$, a Brazilian type of selective and 
sustained attention test $(\mathrm{SSAT})^{16}$, and Brazilian type of school achievement test $(\mathrm{SAT})^{17}$, a Brazilian type of arithmetic proof $(\mathrm{AP})^{18}$ and a protocol of calculation and problem solving $(\mathrm{PC})^{19}$. Patient's scores were compared to normative data.

\section{Sustained and selective attention test}

This test assesses the ability of the subject to keep his attention focused on the task during a period and is designed to measure the speed and accuracy in performing a simple task of target selection ${ }^{16}$.

\section{School achievement test}

This test provides an objective assessment of the essential abilities to school performance, more specifically, writing, arithmetic and reading, according to school age and Brazilian school policies ${ }^{17}$. The test provides, for each item, a raw score which corresponds to the sum of correct items. This score generates a category (inferior, medium and superior) out of the relation of the raw score and school level. The raw scores were used in order to establish correlations with the neuropsychological variables.

\section{Mathematical tests}

$\mathrm{AP}, \mathrm{PC}$ and the arithmetic subtest of SAT (arithmetic) evaluate the following math skills: lexical and syntactic skills, numeric magnitude recognition), math operations (addition, subtraction, multiplication and division) and mathematical reasoning problems. All these evaluations are made with increasing levels of difficulty ${ }^{17-19}$. AP and PC generate a raw score from the number of correct items in the test. These tests do not generate categories. AP was used only in the correlations with the neuropsychological variables and with the remaining tests of mathematical performance. The PC results were considered altered when there were more than $50 \%$ of wrong answers in each subtest.

\section{Developmental dyscalculia diagnosis}

The diagnosis of DD was done through clinical observation (academic transcript, evaluation of teaching and student's motivation to learn mathematic) and analysis of the results. We considered individuals with DD those with normal intelligence and adequate learning who had lower scores in SAT (inferior category) and PC (more than 50\% of the subtests altered).

\section{Data analysis}

The Statistical Package for Social Sciences Release (SPSS 16.0) for Windows (SPSS, 2008) was used for data analysis. Results of MA were correlated with clinical and neuropsychological data through the following non-parametric statistical tests: Mann-Whitney, Kruskal-Wallis and Pearson's correlation coefficient ( $\mathrm{p}<0.05$ was considered significant).

\section{RESULTS}

\section{Clinical and demographic characteristics}

The mean age was 11.4 years (SD 2.2). Twenty two patients $(56.4 \%)$ were male. School years ranged from 2 to 11 years, with an average of 6.1 years (SD 2.25). Only 10 patients (25.7\%) have failed school (1-2 times in average). The main caregiver was the mother in 37 patients $(94.9 \%)$, with a mean school level of 9.6 years (SD 4.3).

Epilepsy duration ranged from 10 to 120 months, with an average of 49.1 months (SD 27.1). Family history of epilepsy was negative in 29 patients (74.4\%). Twenty five patients (64\%) had no seizures in the last year and 11 patients (28\%) had a few seizures. Twenty patients (51\%) had generalized seizures, 13 patients (33\%) had focal seizures and 6 patients $(15 \%)$ multiple seizures. Thirty three patients (84\%) used only one AED, 5 patients (12\%) used more than one AED and one patient $(2.5 \%)$ did not go under drug treatment.

\section{Neuropsychological evaluation}

Table 1 presents data on the IQ of the sample.

Eight patients $(20.5 \%)$ have below average results in the SAT.

SAT were below average in the following percentages $(\mathrm{N}$ $\%)$ : total (23-59), reading (25-64.1), writing (23-59) and arithmetic (24-61.5).

Considering the diagnosis criteria for DSM-IV for DD, 21 patients $(53.8 \%)$ had DD. Table 2 describe the results of the PC.

There was no statistically significant correlation between the types of seizures, seizure frequency, number of AEDs, duration of epilepsy and MA. There was a positive correlation between MA and the level of reading, attention and IQ.

Tables 3, 4 and 5 show the correlations between MA and IQ, attention and reading skills, respectively.

Correlation between IQ and MA was different depending on the arithmetic skill analyzed. In the SAT (arithmetic), there was a statistically significant correlation between all subtypes of IQ and performance on this test. In the AP, there was only one correlation with the MA and progressive speed index (PSI). In the WISC (arithmetic), only the performance

Table 1. Intelligent quocient (IQ) of the sample.

\begin{tabular}{lcccc} 
& Minimum & Maximum & Mean & SD \\
\hline Full scale (FSIQ) & 71.0 & 138.0 & 97.7 & 16.0 \\
Verbal (VIQ) & 70.0 & 146.0 & 101.5 & 14.8 \\
Performance (PIQ) & 9.0 & 123.0 & 91.9 & 20.1 \\
$\begin{array}{l}\text { Processing speed } \\
\text { index (PSI) }\end{array}$ & 64.0 & 149.0 & 96.3 & 19.3 \\
$\begin{array}{l}\text { Freedom from } \\
\text { distractibility index (FDI) }\end{array}$ & 64.0 & 143.0 & 89.3 & 19.5 \\
\hline
\end{tabular}


Table 2. Percentage of correct answers in problem solving.

\begin{tabular}{lcccc}
\hline & Minimum & Maximum & Mean & SD \\
\hline Alphabetical reading & 0.0 & 100.0 & 79.2 & 27.1 \\
Arithmetic reading & 0.0 & 100.0 & 85.0 & 25.9 \\
Numeric magnitude & 0.0 & 100.0 & 84.2 & 35.0 \\
Addition & 0.0 & 100.0 & 79.0 & 29.5 \\
Subtraction & 0.0 & 100.0 & 52.4 & 28.1 \\
Multiplication & 0.0 & 86.0 & 39.0 & 34.6 \\
Division & 0.0 & 100.0 & 42.2 & 38.3 \\
Problem solving & 0.0 & 100.0 & 51.6 & 29.3 \\
\hline
\end{tabular}

intelligent quocient (PIQ) did not show correlation with MA. In the PC there was no relation between the different IQs and abilities in alphabetic reading, arithmetic reading and numeric magnitude. However, there was a positive correlation with math operations (addition, subtraction, multiplication and division) and problem solving, especially related to full scale intelligent quocient (FSIQ), verbal intelligent quocient (VIQ) and PSI.

There was a positive correlation between attention and the MA in the three Math tests used, except for the arithmetic test from WISC.

Likewise, there was a positive correlation between reading ability and the MA, except for the arithmetic test from WISC and numeric magnitude in PC.
Table 4. Correlation between attention and mathematical ability.

\begin{tabular}{lcc}
\hline & SSAT & $\mathrm{p}^{*}$ \\
\hline SAT (Arithmetic) & 0.729 & $\mathbf{0 . 0 0 0}$ \\
Arithmetic proof & 0.536 & $\mathbf{0 . 0 0 2}$ \\
Arithmetic (WISC) & 0.261 & 0.109 \\
Alphabetical reading & 0.490 & $\mathbf{0 . 0 0 6}$ \\
Arithmetic reading & 0.426 & $\mathbf{0 . 0 1 9}$ \\
Numeric magnitude & 0.418 & $\mathbf{0 . 0 2 2}$ \\
Addition & 0.560 & $\mathbf{0 . 0 0 1}$ \\
Subtraction & 0.558 & $\mathbf{0 . 0 0 1}$ \\
Multiplication & 0.519 & $\mathbf{0 . 0 0 3}$ \\
Division & 0.620 & $\mathbf{0 . 0 0 0}$ \\
Problem solving & 0.553 & $\mathbf{0 . 0 0 2}$ \\
\hline
\end{tabular}

${ }^{\star} p<0.05$; raw scores; percentual of correct answers.

\section{DISCUSSION}

Our final sample consisted of 39 CAIE, with a mean age of 11.4 years, without structural brain lesions and with normal neurological examination and normal or borderline intelligence. There was an equal representation of both genders and most patients $(25$ - 64\%) had no seizures during the last year. There was a predominance of generalized seizures.

MA was below average in more than half of cases. The worst results were found in math operations, especially multiplication and division, similar to that observed by Sart et al. ${ }^{12}$. These authors have shown both spatial and operating

Table 3. Correlation between intelligent quocient (IQs) and mathematical ability.

\begin{tabular}{|c|c|c|c|c|c|}
\hline & $\begin{array}{c}\left.\mathrm{FSQ}\right|^{* *} \\
\mathrm{p}^{*}\end{array}$ & $\begin{array}{c}\text { VQI** } \\
p^{*}\end{array}$ & $\begin{array}{c}\mathrm{PIQ}^{* *} \\
\mathrm{p}^{*}\end{array}$ & $\begin{array}{c}\text { PSI** } \\
p^{*}\end{array}$ & $\begin{array}{c}\text { FDl** } \\
p^{*}\end{array}$ \\
\hline \multirow[t]{2}{*}{ SAT (Arithmetic) } & 0.626 & 0.487 & 0.353 & 0.488 & 0.322 \\
\hline & 0.000 & 0.002 & 0.028 & 0.002 & 0.045 \\
\hline \multirow[t]{2}{*}{ Arithmetic proof } & 0.345 & 0.294 & 0.096 & 0.433 & -0.043 \\
\hline & 0.062 & 0.115 & 0.615 & 0.017 & 0.821 \\
\hline \multirow[t]{2}{*}{ Arithmetic (WISC) } & 0.582 & 0.619 & 0.253 & 0.818 & 0.561 \\
\hline & 0.000 & 0.000 & 0.120 & 0.000 & 0.000 \\
\hline \multirow[t]{2}{*}{ Alphabetical reading } & 0.337 & 0.236 & 0.043 & 0.263 & 0.252 \\
\hline & 0.069 & 0.210 & 0.821 & 0.161 & 0.179 \\
\hline \multirow[t]{2}{*}{ Arithmetic reading } & 0.303 & 0.216 & 0.064 & 0.243 & 0.079 \\
\hline & 0.103 & 0.252 & 0.738 & 0.196 & 0.678 \\
\hline \multirow[t]{2}{*}{ Numeric magnitude } & 0.265 & 0.046 & 0.140 & 0.077 & 0.131 \\
\hline & 0.157 & 0.808 & 0.460 & 0.686 & 0.489 \\
\hline \multirow[t]{2}{*}{ Addition } & 0.405 & 0.388 & 0.118 & 0.301 & 0.130 \\
\hline & 0.026 & 0.034 & 0.535 & 0.106 & 0.493 \\
\hline \multirow[t]{2}{*}{ Subtraction } & 0,421 & 0.374 & 0.059 & 0.395 & 0.117 \\
\hline & 0.020 & 0.042 & 0.756 & 0.031 & 0.537 \\
\hline \multirow[t]{2}{*}{ Multiplication } & 0.553 & 0.439 & 0.377 & 0.473 & 0.159 \\
\hline & 0.002 & 0.015 & 0.040 & 0.008 & 0.401 \\
\hline \multirow[t]{2}{*}{ Division } & 0.455 & 0.423 & 0.182 & 0.454 & 0.193 \\
\hline & 0.012 & 0.020 & 0.337 & 0.012 & 0.306 \\
\hline \multirow[t]{2}{*}{ Problem solving } & 0.493 & 0.427 & -0.019 & 0.377 & 0.188 \\
\hline & 0.06 & 0.019 & 0.922 & 0.040 & 0.321 \\
\hline
\end{tabular}

*p<0.05; **Pearsonás correlation coefficient; raw scores; percentual of correct answers. FSIQ: full scale; VIQ: verbal; PIQ: performance; PSI: processing speed index; FDI: freedom from distractibility index. 
Table 5. Correlation between reading skill and mathematical ability.

\begin{tabular}{lcc}
\hline & Reading SAT & $\mathrm{p}^{*}$ \\
\hline SAT (Arithmetic) & 0.690 & $\mathbf{0 . 0 0 0}$ \\
Arithmetic proof & 0.870 & $\mathbf{0 . 0 0 0}$ \\
Arithmetic (WISC) & 0.290 & 0.074 \\
Alphabetical reading & 0.848 & $\mathbf{0 . 0 0 0}$ \\
Arithmetic reading & 0.905 & $\mathbf{0 . 0 0 0}$ \\
Numeric magnitude & 0.330 & 0.075 \\
Addition & 0.901 & $\mathbf{0 . 0 0 0}$ \\
Subtraction & 0.733 & $\mathbf{0 . 0 0 0}$ \\
Multiplication & 0.550 & $\mathbf{0 . 0 0 2}$ \\
Division & 0.564 & $\mathbf{0 . 0 0 1}$ \\
Problem solving & 0.703 & $\mathbf{0 . 0 0 0}$ \\
\hline
\end{tabular}

${ }^{*} p<0.05$; raw scores; percentual of correct answers.

errors, primarily related to math operations, misalignment of numbers in columns or subtracting the minuend from subtrahend, number dysgraphia or the inappropriate use of space for calculation; incorrect reading of the mathematical signs and error in processing the calculation. Our findings were also similar to those described in the literature related to number reading ${ }^{11}$. CAIE had problems mainly in alphabetical reading of numbers, especially in increasing degrees of complexity. Even though our results were not correlated with a control group, this prevalence must be considered high when compared with the general literature of DD (5$6 \%$ of scholars) ${ }^{6}$, and results are clearly discrepant from the expected in a healthy sample. There is no known prevalence of DD in childhood idiopathic epilepsy.

There was no positive correlation between MA and seizure type, seizure frequency, the number of AEDs or the disease duration, so the clinical variables of epilepsy were not related to more specific difficulties in mathematics, which reinforces the hypothesis that epilepsy and dyscalculia are disorders with a common neurobiological basis and one is not the result from the other. Of course, our sample were of patients with well controlled epilepsy on monotherapy. We know that those variables must worsen cognitive function in many aspects ${ }^{5}$ and, probably, mathematical abilities.

However, there was a positive correlation between MA and the level of reading, attention and IQ. This correlation is higher for calculation. This can be explained by the complexity of the cognitive functions which are necessary to implement this arithmetic operations, such as verbal and graphic information processing; perception; recognition and production of numbers; number/symbol representation; visual-spatial discrimination; attention; short and long-term memory and syntax reasoning ${ }^{19}$.

An issue that must also be considered is the known comorbidity among dyslexia, $\mathrm{ADHD}$ and $\mathrm{DD}^{6}$. Although this study did not intend to diagnose these comorbidities, the tests used are correlated with them. These results suggest that the specific difficulty with math skills includes a set of neuropsychological changes that need to be explored for more accurate diagnosis.

We should emphasize that the term DD does not encompass the whole mathematics, but the arithmetic skills. As well as mathematics, arithmetic involves the integration of a series of complex cognitive upper and lower brain functions.

ILAE defines epilepsy as a brain disorder characterized by an enduring predisposition to generate epileptic seizures and by the neurobiological, cognitive, psychological and social consequences of this condition ${ }^{20}$. According to this concept, cognitive changes are a result of epilepsy. But it is still not very clear whether the cognitive changes are a symptom of epilepsy or if both are part of a common underlying brain disease.

Possible explanations for this association between cognitive impairment and epilepsy include structural and physiological aspects, such as the impact of generating lesions of symptomatic epilepsy, the influence of the types of seizures, the frequency of seizures, interictal discharges, as well as the effects the AED. But none of these effects isolated can be responsible for this prevalent association, even in cases where there is a direct relationship as the slow wave status epilepticus of sleep, in which the epileptiform discharges are seen as responsible for cognitive impairment. Besides, there is evidence that children and adolescents with epilepsy exhibit cognitive deficits before the onset of the disease ${ }^{3}$. Another contributing factor is that the process of epileptogenesis in the developing brain, through synaptic plasticity, would generate changes in excitatory and inhibitory neurotransmitters, promoting cognitive dysfunction ${ }^{4}$.

Thus, researchers believe that all the factors described above probably act differently in the pathogenesis of cognitive impairment in these patients. Other factors such as disease stigma, overprotective parents, school absenteeism and low self-esteem, along with cognitive impairment, may also be responsible for most learning difficulties and lower academic performance that were observed in these patients.

This study did not aim to describe and analyze the etiologic factors for cognitive difficulties in mathematics, not only by their multifactorial presentation but also by the limitations of the study design. It only describes the characteristics and magnitude of these changes and their correlation with neuropsychological functioning.

This sample, which consisted of CAIE with fewer or no seizures, in monotherapy and without a defined etiology, similar to the sample described by Canavese et al. ${ }^{11}$ and Sart et al. ${ }^{12}$, who studied benign epilepsies of childhood where patients have fewer crises and do not always use AEDs, exhibited a low MA profile. Because of it, in spite of knowing the potential effects of clinical variables of epilepsy on cognitive impairment, one could postulate that these aspects should not be exclusive determinants of these 
alterations in these patients. And that probably epileptiform changes in patients with epilepsy are not restricted to a specific area, and cover a complex network of neural circuits, since even in epileptic affecting different brain locations and with different genetic determinants, patients had the same problems, the cognitive impairment. Epilepsy is a disease of wide spectrum, and maybe its pathogenesis affect other brain areas involved in cognitive processes, through changes in neurotransmitters, modulation and synaptic plasticity.

In conclusion, it is necessary to carry out more comprehensive studies in this area with a larger number of patients and control group in order to better understand how mathematical learning occurs in these patients. The causes of cognitive impairment and low MA in these patients are still not very clear but there is evidence that the problem exists and must be identified early, especially when there is coexistence with other cognitive disorders, like attention deficit and reading problems. The cognitive prognosis of these patients is even worse when these disorders are present. The answers to these questions will allow the development of cognitive and educational measures suited to this population, in order to improve their academic performance and consequently their quality of life, minimizing the effects of a disease that can often be limiting, such as epilepsy.

\section{ACKNOWLEDGEMENTS:}

We would like to thank Mariana Girão Tauffer for the English revision.

\section{References}

1. Guerreiro CAM, Guerreiro MM, Cendes F, Lopes-Cendes I. Considerações gerais. In: Guerreiro CAM, Guerreiro MM, Cendes F, Lopes-Cendes I (Eds.). Epilepsia. 3a Edição. São Paulo: Lemos Editorial, 2000:1-10.

2. Guerrini, R. Epilepsy in children. Lancet 2006;367:499-524.

3. Berg AT. Epilepsy, cognition and behavior: the clinical picture. Epilepsia 2011:52(Suppl I):S7-S12.

4. Brooks-Kayal A. Molecular mechanisms of cognitive and behavioral comorbidities of epilepsy in children. Epilepsia 2011:52(Suppl I):S13-S20.

5. Elger CE, Helmstaedter C, Kurthen M. Chronic epilepsy and cognition. The Lancet 2004;3:663-672.

6. Shalev RS, Gross-Tsur V. Developmental Dyscalculia. Pediatr Neurol 2001;24:337-342.

7. American Psychiatric Association. Manual diagnóstico e estatistico de transtornos mentais: DSM-IV. $4^{a}$ edição, texto revisado. Porto Alegre: Artmed, 2002.

8. Aster M. Developmental cognitive neuropsychology of number processing and calculation: varieties of developmental dyscalculia. European Child Adol Psychiatr 2000;9(Suppl II):S41-S57.

9. Bastos JA. Discalculia: transtorno específico da habilidade em matemática. In: Rotta NT; Ohlweiler L; Riesgo RS. Transtornos da aprendizagem - abordagem neurobiológica e multidisciplinar. Rio Grande do Sul: ARTMED, 2006:195-206.

10. Vasconcelos L. Neuropsicologia da competência Matemática. In: Valle LELR (Ed). Temas multidisciplinares de neuropsicologia. São Paulo: Robe Editorial, 2003:493-502.
11. Canavese C, Rigardetto R, Viano V, et al. Are dyslexia and dyscalculia associated with Rolandic epilepsy? A short report on ten Italian patients. Epileptic Disord 2007;9:432-436.

12. Sart ZH, Demirbilek V, Korkmaz B, Slade PD, Dervent A, Townes BD. The consequences of idiopathic partial epilepsies in relation to neuro-psychological functioning: a closer look at the associated mathematical disabilities. Epileptic Disord 2006;8:24-31.

13. Comission on Classification and Terminology of the International League Against Epilepsy. Proposal for revised clinical and electroencephalographic classification of epileptic seizures. Epilepsia 1981;22:489-501.

14. Comission on Classification and Terminology of the International League Against Epilepsy. Proposal for revised classification of epilepsies and epileptic seizures. Epilepsia 1989;30:389-399.

15. Wechsler D. WISC-III: Escala de inteligência Wechsler para crianças: manual. $3^{a}$ ed.; São Paulo: Casa do Psicólogo, 2002.

16. Cambraia SV. Atenção concentrada. Manual. São Paulo: Vetor, 2003.

17. Stein, LM. TDE: Teste de desempenho escolar: manual para aplicação e interpretação / São Paulo: Casa do Psicólogo, 1994.

18. Capovilla AGS, Raad AJ, Berberian AA, Dias NM, Trevisan BT. Avaliação de aritmética em crianças de $1^{a}$ a $4^{a}$ série: prova de aritmética. Capovilla AGS, Capovilla FC (Eds.). Teoria e pesquisa em avaliação neuropsicológica. São Paulo: Editora Memnon, 2007:45-53.

19. Bastos JA. O Cérebro e a matemática. $1^{a}$ edição. São José do Rio Preto: Edição do Autor, 2007.

20. Fisher RS, van Emde Boas W, et al. Epileptic seizures and epilepsy: definitions proposed by the International League Against Epilepsy (ILAE) and the International Bureau for Epilepsy (IBE). Epilepsia 2005;46:470-472. 